\title{
Army, Navy, Air Force and Research? The Vocation of Scholarship as an Applied Discipline in the Canadian Forces
}

\author{
Catherine Bates \\ Directorate of Aerospace Equipment Program Management
}

\begin{abstract}
This article is a personal and professional reflection on scholarship and research as applied to a very large and mechanistic organization - the Canadian Forces. A specialist cadre of officers within the Canadian Forces is dedicated to the applied discipline of Training Development. Training Development is the practical application of adult education theory and, in an academic institution, would normally provide ample scope for research. However, the shortage of professional Training Development Officers in the Canadian Forces leaves little time for research given the urgent requirement to train and deploy everincreasing numbers of Army, Navy and Air Force personnel to theatres of operations abroad. Those officers who practice scholarship through research pursuits often do so to satisfy personal rather than professional goals. The engagement in professional research projects is filled with challenges that include identification of key stakeholders, selection of a topic, and the ethics of rationalizing personal areas of academic interest with military areas of need. The result is a focus on applied rather than academic research. To ethically conduct applied research using Canadian Forces subjects requires the active participation of unrelated departments and the use of both personal and work time to complete the research task. The greatest gains in efficiency can be achieved through position related research. Although there are challenges associated with the pursuit of scholarship in a military setting, there is also ample scope for examination of topic areas not previously addressed through research. The article concludes with recommendations for research into institutional effectiveness, leader experiences and future requirements through a combination of position related and personal interest generated research.
\end{abstract}

\section{Introduction}

I have been a member of the Canadian Forces for 23 years in both the Army and the Air Force. I must now consider how to continue to serve as I begin my doctoral studies in educational leadership and policy. This article is a personal and professional reflection on the vocation of scholarship as an applied discipline in the Canadian Forces. Although there are many potential and actual areas of research within the Canadian Forces, the main discussion areas in this paper are leadership and organizational development in training and education.

Catherine Bates is a Training Development Officer in the Canadian Forces and a doctoral candidate in the Joint $\mathrm{PhD}$ Program in Educational Studies at the University of Brock. Her research interests include the impact of educational policy and leadership on the organization, instructional design, and instructor development. 
My experiences in the Canadian Forces are unique, and one of the reasons that I have chosen to pursue doctoral studies in education is to understand my own organization's training and education leadership and policy structures. Although I have a great deal of experience working within these structures and have worked as a policy officer, instructional designer, and training manager, I believe that we do not often pause to reflect on why we are doing what we do, and how it is impacting on the people and the organization that we serve. On reflection, I now believe that I have ignored the impact that my membership in the Canadian Forces has had on my vocation as a scholar to the extent that I merely use workplace scenarios to provide positive and negative case studies. Rarely have I taken a holistic approach to applying educational theories, principles and concepts to describe the Canadian Forces' Individual Training and Education System and the impact that leadership and organizational development have on it. Once described, these same theories, principles and concepts could be used to answer persistent and intriguing questions about educational leadership and policy in the Canadian Forces.

This paper reflects on the vocation of scholarship in the Canadian Forces through a discussion of the meaning of scholarship and the associated research challenges. It concludes with practical considerations affecting research and scholarship applied to the potential for research and scholarship in the field of leadership and policy in a military educational organization. The Training Development Branch, as the specialized branch within the Canadian Forces dedicated to training and education, is highlighted as an area of particular interest to me, personally as a Training Development Officer and professionally as a rich source of unexploited researchers. Although this discussion is a profoundly personal reflection on scholarship, I believe that it also holds insights into the application of scholarship to a very large, hierarchical, and mechanistic organization that would be applicable to other similar organizations.

\section{Scholarship in the Canadian Forces}

In this section, I will set the scene by describing the units and groups within the Canadian Forces that conduct research and whose policies have an influence on scholarship. I will then examine what scholarship means to me as a Training Development Officer. I am aware that when I discuss scholarship as an applied and creative pursuit in the service of the organization, I might appear idealistic, however, these concepts reflect my values and beliefs, and they will continue to inform my choice of research for many years to come. Following this section, I will move into an examination of the challenges of research in my very large and hierarchical organization.

\section{Background}

Formal scholarship in education is actively pursued in certain sectors of the Canadian Forces such as Royal Military College, Canadian Forces Leadership Academy, Canadian Forces College, Canadian Defence Academy, and Directorate of Human Resources Research and Ethics. However, it is not carried out elsewhere. The Training Development Branch has one officer with a doctorate degree in education and four other Training Development Officers who 
are at various stages of their doctoral studies. It is important to note that many of the approximately 120 Training Development Officers in the Canadian Forces have Master's degrees in Education (many with more than one in sub-specialties of education such as Evaluation and Measurement, and Distance Education), however an undergraduate degree (ideally in education) is the entry-level requirement. The doctoral research undertaken by Training Development Officers is neither centrally coordinated nor used to feed back into the Canadian Forces as an organization since the decision to pursue doctoral studies is a personal one and not sponsored by the Canadian Forces (although reimbursement of tuition is available).

\section{Scholarship as an applied discipline}

Scholarship in the Canadian Forces is necessarily an applied rather than a theoretical discipline. Applied scholarship results in research products that include recommendations and implementation plans based on findings that guide the way ahead. Recommendations can include suggestions to revise policy, doctrine, training, education, organizational structures, or procedures. The policy governing research involving human subjects supports the concept of applied scholarship by allowing it when "the research substantially benefits the Department of National Defence or the Canadian Forces in the pursuit of operational tasks and missions or departmental priorities" (Defence Administrative Order and Doctrine, article 5061). This paper is itself an example of applied scholarship as it examines the vocation of scholarship in the Canadian Forces and concludes with a recommended research plan to address an identified gap. The officer corps that would mainly address this research gap through applied scholarship is the Training Development Branch representing all Training Development Officers.

The Training Development Branch of the Canadian Forces is a specialist cadre of officers selected and trained to advise Commanders on the principles and applications of adult education, change management, and instructional design. Training Development Officers with advanced degrees are generally not pursuing theoretical research because the Canadian Forces is concerned with the applied discipline of occupational training. Occupational training is the field of training development dedicated to analyzing job tasks, converting them into precise skills and knowledge, and describing them as performance objectives with observable and measurable standards and conditions under which they are performed. The performance standards are then used to create detailed training plans that include instructional designs and strategies, assessment instruments, and activities (e.g., case studies, role-plays, lessons/lectures, exercises, guided discussions, group work, etc.). Occupational training feeds back into the training and education system through evaluation and validation of the training that was designed and implemented.

In other large Canadian corporations, the training development staff members concentrate on creating and managing training for their employees and leave the research and development departments to conduct theoretical research on their main lines of business. The Canadian Forces' main line of business is leadership and operations. Of the approximately 60,000 Regular Force members serving in the Canadian Forces, 120 are applied to the training development 
function. The result is less than $1 \%$ of the Canadian Forces personnel applied to training development tasks, with the remaining 99\% applied to other core functions (NB: Other officers such as lawyers, doctors, nurses, chaplains, public affairs officers, and personnel selection officers are also engaged in specialized functions.). The proportion of the Canadian Forces applied to operational functions compared to specialized functions indicates a focus on application rather than theory. Canadian taxpayers have never demanded a greater contribution of specialist officers in world conflicts, but often support and demand a greater contribution of operational combat-ready Army, Navy, and Air Force personnel. Training shortfalls are often the reason that Canada cannot deploy as many units as requested to assist in worldwide conflicts. The Training Development Branch is working at maximum capacity simply to supply trained soldiers, sailors, and air personnel to operations. There is no surplus capacity in the Training Development Officer corps for academic pursuits. The founder of modern peacekeeping, Lester B. Pearson believed that: "In facing the choice of peace or extinction, man must renounce predatory nationalism and look to the primacy of world concerns to bring about peace and security for all" (Lester Pearson: Nobel Prize, n.d., section B, para 1). This statement highlights the fact that the Canadian Forces' dedication to peace and security is of prime importance. The application of training to this end is essential. The requirement to maintain a trained military is currently making maximum use of the small cadre of training development specialists who must focus all their efforts on the application of theory rather than advancing the field of knowledge through research. This mandate has so far ensured that scholarship in the Canadian Forces by Training Development Officers remains an applied rather than a theoretical discipline.

\section{Scholarship as a creative art form}

One definition of research is a "studious inquiry or examination, especially investigation or experimentation aimed at the discovery and interpretation of facts, revision of accepted theories or laws in the light of new facts, or practical application of such new or revised theories or laws" (Merriam-Webster On-Line, (n.d.), definition 2). The positivist, who believes that scientific principles would bring about a new higher stage of human advancement (Rohmann, 1999), would favor the idea of collecting facts to prove a theory and to implement a plan of action. Personally, it does not ignite any spark of enthusiasm or motivation in me to conduct research. The humanist, who values the dignity and rationality of human beings (Rohmann, 1999), would prefer a definition of research that includes an element of creativity and exploration. The world of the scholar is the world of ideas. Applied research is the result of ideas that are applied to finding solutions to practical problems, and theoretical research combines with the scholar's attitudes and beliefs to find unique ways of viewing the social world.

As a working definition, my approach to scholarship depends on a curiosity about the world at large and the many fascinating personalities that people it. Berg notes that it is the "various values, moral attitudes, and beliefs that orient people in a particular manner" (Berg, 2004, p. 155). I believe that our values and beliefs cannot be changed, and it is the moral roadmap that we all use to navigate through life. However, improvisation through formal and informal learning 
means that "a person's identity is never fixed; instead it is fluid and ever changing and every individual is composed of multiple, often conflicting identities" (Badali, 2004, p. 2). This paradox of fixed values and beliefs of an evolving identity can be applied to the creative pursuit of research. Openness to new ideas and avenues of exploration is what makes research a creative endeavor rather than simply a methodical investigation. One might even call this an idealist's approach, which would apply if an idealist is defined as "someone in pursuit of an ideal that is beyond the horizon but firmly grasped in the mind" (Rohmann, 1999, p. 190).

In addition to an expression of creativity, research holds a political and moral interest to some scholars. The belief that "inquiry through research is always moral and political" (Finley, 2005, p. 681) reflects a personal desire to serve by adopting and supporting a position. However, the selfish desire to enjoy the process by creating something new from an original idea is compelling. According to Finley, this requires the rigor of "interpersonal, political, emotional, moral and ethical competence" while at the same time employing "intellectual openness and creativity" (2005, p. 683). I believe that a life based on improvisation and creativity can feed the research process and result in deep personal satisfaction. The pursuit of scholarship based on an appreciation of the creative process and a fascination with humanity will lead to scholarship experiences that are both rewarding and motivating.

\section{Scholarship for service}

If applied research in the Canadian Forces is used as the starting point for further dialogue and action, then applied research could be construed as having both an activist and political basis. It could also be used to advance the field of knowledge by suggesting areas of further inquiry. The activist and political nature of research of this nature suggest an element of service to society, either the microcosm of society that is the Canadian Forces, or potentially the larger society that the Canadian Forces serve. Similarly, those members of the Canadian Forces conducting research in the pursuit of their own advanced academic goals are doing so to satisfy professional and/or personal aims. These aims are clearly supported by the Canadian Forces through funded advanced academic upgrading programs, the criteria for acceptance being a desire to improve professional practice, and/or prepare for retirement from the Canadian Forces. Certainly, research conducted for either academic or professional reasons has the potential to convince or persuade the reader or user of the research to adopt the researcher's point of view. If this research is then used either to suggest areas of further study or to ameliorate human performance problems, then the research is in the service of society.

Service to society is reflected in the leadership that all officers in the Canadian Forces are expected to demonstrate, and this includes Training Development Officers as leaders in adult education principles and practices. Educational leadership in a military setting embodies a combination of several leadership styles and models, and when finding its expression in research is best suited to the situational leadership model. Situational leaders are defined as able to adapt leadership style according to requirements of environment and subordinates (Eberman, C., Ahronson, A., \& Catano, V., 2002). The further 
pursuit of doctoral studies implies an even greater call to leadership to apply our area of expertise to our own organization. This reflects the Canadian Forces definition of effective leadership, "directing, motivating and enabling others to accomplish the mission professionally and ethically while developing or improving capabilities that contribute to mission success" (Canadian Defence Academy - Canadian Forces Leadership Institute, 2005).

The selection of a research topic is framed by the ability to find a suitable experimental group and research question that is manageable in terms of time, resources, access, and potential for a successful outcome. As a member of the Canadian Forces and a Training Development Officer practicing applied adult education and training, it would be indulgent and disloyal if I conducted research based on my own attitudes, values, and beliefs. Ultimately, research should be used to serve a greater purpose, whether that is service to the government of Canada or service to society through scholarship. The moderate position is to frame the discourse within our own organization's frame of reference rather than our own. This position would create what Max Weber would consider the valuefreedom that is the avoidance of value judgments that bias research (Rohmann, 1999).

\section{Research in the Canadian Forces}

The discussion that follows describes the challenges of conducting research in the Canadian Forces. The Canadian Forces currently practice a decentralized form of control, and different stakeholders are responsible for research and the processes necessary to conduct the research. Other stakeholder organizations control research including who can do it and how it is done. The access to (and availability of) research data and the future use of the research results will affect what questions to pursue and how to conduct the research. This discussion will lead to the concluding section where I have identified a gap in research that could be addressed despite the challenges described here.

\section{Background}

The Canadian Forces currently practice a decentralized organizational structure. Figure 1 below is an extremely simplified depiction of research responsibilities and inputs in the Canadian Forces. Essentially, all military and civilian members of the Department of National Defence are under the command of Canada's only full General - the Chief of Defence Staff. The Chief of Defence Staff has an operational arm under the command of the Deputy Chief of Defence Staff and an administrative arm under the command of the Vice Chief of Defence Staff. The Vice Chief of Defence Staff controls the day-to-day conduct of the Canadian Forces. To do this he commands various Assistant Deputy Ministers who in turn command units and formations applicable to their area of influence. Of interest to this discussion is the Assistant Deputy Minister Human Resources (Military) (there is a corresponding Assistant Deputy Minister Human Resources (Civilian) who manages all aspects of the civilian Defence Team). The Assistant Deputy Minister Human Resources (Military) commands all of the units that conduct research of interest to this discussion, except for the Assistant Deputy Minister Finance and Corporate Services, who commands the Policy Group that issues all 
Defence policy, including the one on Research Involving Human Subjects, and manages the Security and Defence Forum that funds 12 centres of expertise and one Chair of Defence Management Studies at universities across Canada (discussed below).

Figure 1: Canadian Forces Research Responsibilities and Inputs

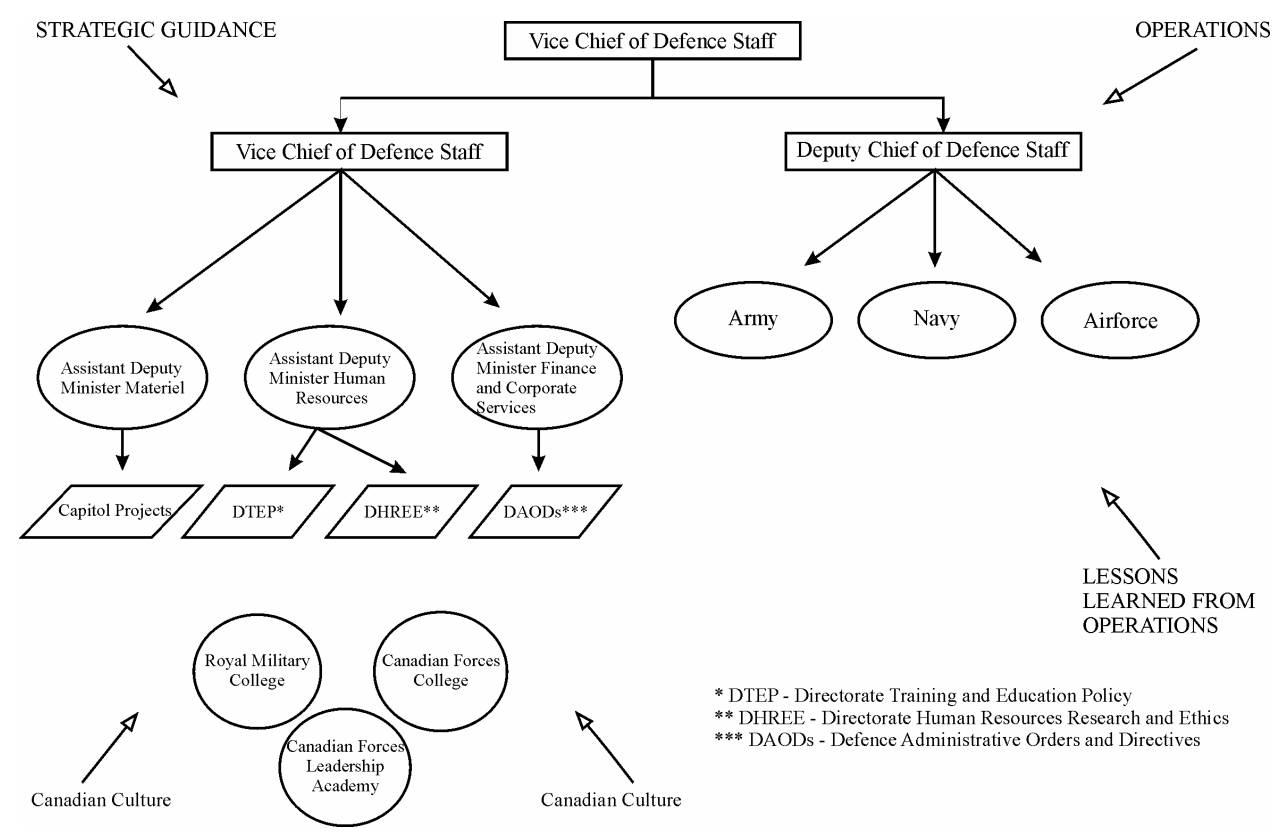

\section{The challenge of decentralization}

Decentralization has grown throughout the years in response to pressure from Commanders to control their resources (i.e., human, financial, and material) to ensure a quick response to emerging issues. Overall, the decentralization of many Canadian Forces' functions has had a positive impact on the Department of National Defence; however, it has also resulted in duplication of effort in many areas including policy and research. The establishment, just a few years ago, of the Canadian Defence Academy with the Canadian Forces Leadership Institute, Royal Military College, and Canadian Forces College was an attempt to reestablish control of education, continuing studies, leadership training, and military professional development. However, the Directorate of Training and Education Policy still controls the management of occupational training and the Canadian Forces Individual Training and Education System.

The Canadian Forces Individual Training and Education System is a systematic approach to a training model that controls quality, quantity, and resources dedicated to training and education in the Canadian Forces. This includes a research and development component directly related to training and education policy. The product of the research and development process in the Directorate of Training and Education Policy is the writing, promulgation, and promotion of the multi-volume Manual of Individual Training and Education. As policy, the Manual reflects the combined efforts of the Directorate whose 
mandate is to guide all phases of the systematic approach to training. The Directorate employs a large number of Training Development Officers who are the Canadian Forces' specialists in adult education, change management, and instructional design. Through decentralization of training, Training Development Officers are also employed throughout the Canadian Forces in all groups and commands. Once Training Development Officers become members of their own particular unit, the chain of command effectively eliminates all but a mentoring relationship with the Directorate of Training and Education Policy from these officers' day-to-day work. Any research conducted by these officers would be on behalf of their unit rather than on behalf of the Canadian Forces or the Training Development Branch as a whole. The research would be applied to a training or education problem relating to program evaluation, selection of a suitable instructional strategy, or a solution to a human performance problem.

Another decentralization challenge is gatekeepers. Data gatekeepers quickly develop a proprietary attachment to their research, and access is sometimes limited to units within the same formation (e.g., major capitol projects working under Assistant Deputy Minister Material) or environment (e.g., squadrons within the Airforce). Although the reports produced by these units are easy to find on the Internet, either the organization or the individual researcher holds the data that generated the findings. New researchers might unintentionally duplicate existing data if they are not aware that similar research has already been done, or if dissimilar research produced useful data for a new research question. Some examples of the types of available data include; recruiting data, validation studies, Quality of Life program survey results, informal in-house data collection, evaluation reports, Ministerial Inquiries, Redresses of Grievance, harassment prevention and mediation statistics, operational lessons learned, and exit interviews.

Policy gatekeepers affect the ability to conduct research on Canadian Forces' members. The Policy Group issues the policy on research involving human subjects, but it is sponsored by the Directorate of Health Operations because the types of human subjects normally experimented upon are involved in medical research. Social science research is included in this policy when the aim is either to study behavior or to solicit, acquire or use confidential information or opinions in research (Defence Administrative Order and Doctrine, article 5061). If a researcher wants to use a survey to collect qualitative data, the Directorate of Human Resources Research and Ethics would approve and issue it as survey gatekeepers. This is done to minimize the impact of too many surveys consuming too much time for the average Canadian Forces' member. However, if a survey request is approved, this directorate will issue it to all Canadian Forces' members. In this case, timing is a challenge because the survey, with all researchers' individual questions, is only issued yearly.

\section{Role of Canadian Forces' Leadership Institute}

The research conducted by the Canadian Forces' Leadership Institute by contract researchers is a new initiative in support of the recently issued Leadership in the Canadian Forces: Doctrine and Leadership in the Canadian Forces: Conceptual manuals. As mentioned previously, leadership can be considered one of the Canadian Forces' main areas of interest, and the production of the new 
leadership manual to replace the one written in the 1970's was an area of intense dialogue during the redesign of the officer and non-commissioned officer professional development system that was recently completed. The ability to select and train leaders efficiently (with due regard to human, financial, and material resources) and effectively (resulting in a trained and educated person able to lead) is vitally important to all armed forces since it is leadership that makes the difference between success and failure in operations, both at home and abroad.

The research areas of the Canadian Forces Leadership Institute are highlighted in Table 1, and demonstrate the depth and breadth of the field (Canadian Defence Academy - Canadian Forces Leadership Institute, 2005).

Table 1

Canadian Forces' Leadership Institute Research Areas

\begin{tabular}{lll}
\hline \multicolumn{1}{c}{ Topic Areas } & \multicolumn{1}{c}{ Purpose } & \multicolumn{1}{c}{ Output } \\
\hline Leader & Integrate the models of & Applied reports describing an \\
Development & differentiated competencies and & integrated, sequential approach \\
& processes with Canadian Defence & to leader development across the \\
& Academy with models of adult & various developmental periods \\
& learning to guide Canadian Forces & and professional development \\
& professional development programs. & concepts.
\end{tabular}

Leader Develop detailed model/description Comprehensive reports

Effectiveness of the leadership process required to describing the major components ensure institutional effectiveness of the task cycle and change across various contingencies. management processes incorporated in Leadership in the Canadian Forces.

Differentiated Develop detailed model/description Leader Roles, of how leadership differs across the Responsibilities Canadian Forces starting with the and distinctions of leading people and Competencies leading the institution.

Two subordinate manuals (People and Institution) to guide professional development and other human resources programs, and supporting documents detailing the model and key components.

Overarching Develop/update broad framework Conceptual Leadership Framework incorporating theories, concepts, and research relevant to leadership in the military context.

Inclusion in Leadership in the $\mathrm{CF}$ and supporting academic documents summarizing relevant literature and Canadian Forces philosophy of effective leadership.

Socialization Develop detailed model/description and Culture of the major factors and processes involved in military socialization and the alignment of culture to the profession of arms ethos.

Notice that the outputs of the research all have an applied focus. Although there is a mandate to conduct research on institutional effectiveness, leader experiences, and future requirement, there are currently no published reports on 
those topics. These areas are discussed later in this article as areas for potential research.

\section{Other research sites}

In addition to the research conducted at the Canadian Forces' Leadership Institute, several other sites are concerned with research on leadership and organizational development. The Security and Defence Forum funds 12 centres of expertise and one Chair of Defence Management Studies at universities across Canada. Table 2 lists the participating universities and their research agenda. A review of the articles published by the Canadian Forces' Leadership Institute indicates that some contract researchers are members of the universities participating in the Security and Defence Forum. Similar to the civilian contract researchers at the Canadian Forces Leadership Institute, the researchers at these Canadian universities are almost all civilians except for the occasional officer studying leadership as part of their sponsored Masters of Business

Table 2

Security and Defence Forum Centres of Expertise

\begin{tabular}{|c|c|}
\hline University & Area of Expertise \\
\hline Dalhousie University & Centre for Foreign Policy Studies \\
\hline University of New Brunswick & Military and Strategic Studies Program \\
\hline Université Laval & $\begin{array}{l}\text { L'Institut québécois des hautes études } \\
\text { internationales }\end{array}$ \\
\hline Université de Montréal/McGill & Groupe d'étude et de recherche sur la \\
\hline University & $\begin{array}{l}\text { sécurité internationale (GERSI)/Research } \\
\text { Group in International Security (REGIS) }\end{array}$ \\
\hline Université du Québec à Montréal & $\begin{array}{l}\text { Centre d'études des politiques étrangères } \\
\text { et de sécurité }\end{array}$ \\
\hline Queen's University & $\begin{array}{l}\text { Centre for International Relations, Chair } \\
\text { in Defence Management Studies }\end{array}$ \\
\hline Carleton University & Centre for Security and Defence Studies \\
\hline York University & $\begin{array}{l}\text { Centre for International and Security } \\
\text { Studies }\end{array}$ \\
\hline Wilfrid Laurier University & $\begin{array}{l}\text { Centre for Military, Strategic and } \\
\text { Disarmament Studies }\end{array}$ \\
\hline University of Manitoba & Centre for Defence and Security Studies \\
\hline University of Calgary & Centre for Military and Strategic Studies \\
\hline University of British Columbia & Centre of International Relations \\
\hline
\end{tabular}

Administration degrees. What does this say about the availability and motivation of Canadian Forces members to conduct research? Canadian Forces members are generally available and required to conduct research when undergoing training and education at the Royal Military College (as undergraduate and graduate students) and the Canadian Forces College (in preparation for promotion to senior and general officer ranks). Once they return to their units following training, the operational tempo of the Canadian Forces precludes any sustained research effort. 


\section{Practical Considerations Affecting Research in the Canadian Forces}

The discussion that follows considers the practical factors affecting the selection of suitable research topics for conducting research in one's own organization. The following four factors are immediately applicable to the decision-making process and will greatly influence the selection of areas of research. I believe that these practical matters are vital to consider since the application of research is the main goal and any delay in completing it could potentially render any results superfluous. A proposed research plan follows this discussion and is based on consideration of these factors.

\section{Position-related research}

There are risks and advantages to conducting research on a topic directly related to one's position within the Canadian Forces. An advantage to this approach is the immediate suggestion of research questions based on work that must be done during the course of everyday work. The collection and analysis of data and the reporting of findings does not pose the ethical dilemma of working on a personal research issue during duty time, and any results can be used both to satisfy organizational and personal academic requirements. In my own case, the research issues would concern the selection, design, and deployment of new training in support of the CF18 Modernization Project. This is a major crown project dedicated to modernizing the Canadian Air Force's twenty-year-old fighter aircraft so that it can remain in service until 2017. The risks of this approach include: being posted away from the job before the research is finished, doing the research for expediency sake but not finding any joy in it, investigating a question that does not have any applicability outside of a military setting (e.g., simulation or distance delivery), and getting known for a subject that is not motivating to study in the long-term.

\section{Application of available data to a new research question}

The allure of applying existing data to a new research question is compelling. The types of existing data described in the discussion above (e.g. recruiting statistics, training establishment student achievement and demographic data) are numerous and the advantage is that busy and overworked Canadian Forces members do not have to take time out of their day to serve as research subjects. The difficulty lies in discovering sources of data, getting permission to use the data from the gatekeepers, and deciding if further informed consent is required because the data were taken initially for other reasons. In a chicken or egg type scenario, the formulation of a "great" research question depends on the type of data available, but the type of data available is not readily accessible unless the research question is known.

\section{Solicitation of a sponsor}

As discussed above, there are several organizations dedicated to research. It would be expedient to contact these units to enquire if there are any research projects that they would like to conduct, but that they do not currently have the personnel to support. The Canadian Forces Leadership Institute and the Directorate of Training and Education Policy doubtless have ample research 
questions that might have wide applicability and even existing data. It might be possible to work with one of these units as a sponsor for research, however if the questions they have do not support the researcher's interests or challenge values and beliefs, then long-term work on the assigned area would prove very demotivating. It might therefore result in a conflict between researcher organization and academic institution's goals. The question of who owns the completed research might also arise. Finally, the concept of doing work on behalf of a unit other than one's own during duty hours would challenge the chain of command structure that is essential to the military culture.

\section{Research on an area of personal interest with organizational impact}

A review of the literature directly related to leadership and organizations within a military culture resulted in 58 recent articles. However, there appears to be a gap with respect to leadership and organizational policy in a military education setting as compared with administration and leadership in public/civilian education. The military leadership culture and socialization is very different from that found in a civilian setting and it would be personally rewarding to explore leadership culture and its impact on educational organizations and policy. This type of research in an applied form might suggest changes to policies, processes, organizational development, leadership training and education, or doctrine.

\section{The Research Gap}

The discussion that follows considers areas of potential research in the Canadian Forces on the topics of leadership and organizational development. The results of a preliminary literature review into research on distinctly Canadian studies of leadership within the military organizational culture suggest areas of further exploration based on gaps in the literature. Selecting a research question from the proposed list below would allow for research on an area of personal interest with organizational impact. This type of research would be motivating, reflect my values and beliefs, and serve the organization and my specific workplace.

\section{Review of Canadian Forces' sponsored research for Canadian Forces Leadership Institute}

The Canadian Forces Leadership Institute has three areas of research that they would like to pursue but do not currently have any associated articles or reports. Table 3 lists those areas and shows the purpose of research on those topics and the proposed output. Research in the field of leadership is timely because it would coincide with the promulgation of the new Leadership in the Canadian Forces manual and augment the research conducted by civilian staff researchers at the Canadian Forces Leadership Institute. It would be ideal to conduct research on any of those three topic areas with an applied focus that would benefit the CF18 Modernization Project. This would allay ethical concerns regarding conduct of research on duty time, potential to feedback findings into the organizational system, personal motivation achieved by working on a project that satisfies my goals and reflects my attitudes and beliefs, and reflects the view of scholarship discussed above. 
Table 3

Gaps in Leadership Research

\begin{tabular}{|c|c|c|}
\hline Topic Area & Purpose & Output \\
\hline $\begin{array}{l}\text { Institutional } \\
\text { Effectiveness }\end{array}$ & $\begin{array}{l}\text { Conduct continuous } \\
\text { measurement of the key aspects } \\
\text { of institutional effectiveness } \\
\text { resulting from the application of } \\
\text { leadership and professionalism } \\
\text { concepts with an emphasis on } \\
\text { the operational effectiveness of } \\
\text { formed units. }\end{array}$ & $\begin{array}{l}\text { Applied reports to be used to } \\
\text { test the various models above } \\
\text { and to provide input to } \\
\text { Canadian Forces, and } \\
\text { Department of National } \\
\text { Defence output and outcome } \\
\text { measures. }\end{array}$ \\
\hline $\begin{array}{l}\text { Leader } \\
\text { Experiences }\end{array}$ & $\begin{array}{l}\text { Collect the individual } \\
\text { perspectives of serving or retired } \\
\text { senior leaders examining } \\
\text { specific significant events or } \\
\text { broad commentary across their } \\
\text { career. }\end{array}$ & $\begin{array}{l}\text { Information will be presented } \\
\text { in various forms depending } \\
\text { on the nature/extent of } \\
\text { comments thus ranging from } \\
\text { reports summarizing common } \\
\text { themes drawn from various } \\
\text { observations to individual } \\
\text { articles/monographs such as } \\
\text { the Croatia Board Of Inquiry } \\
\text { Lessons Learned to } \\
\text { comprehensive books. }\end{array}$ \\
\hline $\begin{array}{l}\text { Future } \\
\text { Requirements }\end{array}$ & $\begin{array}{l}\text { Conduct continuous analyses of } \\
\text { emerging issues, trends, and } \\
\text { requirements of institutional } \\
\text { effectiveness based on } \\
\text { examinations of both current } \\
\text { operations and new concepts } \\
\text { from strategic planning across } \\
\text { the security arena. }\end{array}$ & $\begin{array}{l}\text { Applied reports used as input } \\
\text { to both the overarching } \\
\text { leadership and professional } \\
\text { conceptual frameworks and } \\
\text { the various models. }\end{array}$ \\
\hline
\end{tabular}

\section{Potential research topics/questions}

The selection of a research topic is based on the factors discussed above, and by the ability to find a suitable experimental group and research question that is manageable in terms of time, resources, access, and potential for a successful outcome. The following questions/topics are suggested by the research gap described in Table 3 and are manageable:

1. History of power, misuse of power and its impact: case studies of Canadian Forces leaders with great power.

2. The role of power in leadership: A comparison of power in the Canadian Forces with power in other organizations.

3. Organizational culture and the achievement of power and leadership.

4. Case studies of successful leaders and the role that formative experiences as operant conditioning play in the achievement of power.

5. A critical examination of the influence of leadership and organizational culture on education in the Canadian Forces. 
6. The cult of the leader and intended and unintended consequences on organizational policy.

7. A case study of Canadian Forces policy structure: does it reflect a specific model or theory?

8. The devaluation of policy in a decentralized system and the resulting impact.

\section{Conclusion}

Research in the Canadian Forces is certainly a challenge. However, the discovery of a topic that will capture the researcher's interest and hold it throughout the process is equally challenging. I believe that reflection on my personal meaning of scholarship as an applied and creative art form in the service of the Canadian Forces will result in a valuable contribution. Either working within the system and uncovering rich sources of existing data or finding new questions to ask is part of what makes research so rewarding. The satisfaction of intellectual curiosity by finding a solution to a persistent organizational problem is the motivation that keeps a researcher searching for new questions after the first project is complete. A life dedicated to scholarship is therefore self-perpetuating, but only if the scholar remembers why it is being done, if the research challenges are rewarding rather than frustrating, and if every now and then an exciting research question presents itself. I believe that the Canadian Forces will satisfy those conditions and that I have many rewarding years of scholarship ahead.

\section{References}

Badali, S. (2004). Exploring tensions in the lives of professors of teacher education: A Canadian context. Journal of Teaching and Learning 3(1), 1-16.

Berg, B.L. (2004). Qualitative Research Methods for the Social Sciences. Pearson Education Inc.

Canadian Defence Academy - Canadian Forces Leadership Institute (2005). Retrieved on July 21, 2005 from http://www.cda-acd.forces.gc.ca/CFLI/engraph/leadership/qa/qa_e.asp

Defence Administrative Order and Doctrine, article 5061. (n.d.). Research Involving Human Subjects.

Department of National Defence (2005). Newsroom: CF18 Backgrounder. Retrieved on July 28, 2005, from http://www.forces.gc.ca/site/newsroom/view_news_e.asp?id=1601

Eberman, C., Ahronson, A., \& Catano, V. (2002). Integrative leadership models in the military context. CFLI Contract Research Report \#CR01-0080. Kingston, ON: Canadian Forces Leadership Institute.

Finley, S. (2005). Arts-based inquiry: Performing Revolutionary Pedagogy. In N. Denzin (Ed), The Sage handbook of qualitative research, Third Edition (pp. 681-695). Thousand Oaks, CA: Sage Publications.

Lester Pearson: Nobel Prize.(n.d.). Retrieved 17 May, 2006, from http://encarta.msn.com/encyclopedia_761554599_2/Lester_Pearson.html

Merriam-Webster On-Line (n.d.). Retrieved on May 17, 2006, from http://www.m-w.com/

Rohmann, C. (1999). A world of ideas: A dictionary of important theories, concepts, beliefs, and thinkers. The Ballantine Publishing Group. 